\title{
Fossil $\mathrm{CO}_{2}$ emissions in the post-COVID-19 era
}

\author{
Corinne Le Quéré $\left(\mathbb{1}^{1,2} \llbracket\right.$, Glen P. Peters $\circledast^{3}{ }^{3}$, Pierre Friedlingstein $\left(^{4,5}\right.$, Robbie M. Andrew $\left(^{3}\right.$, \\ Josep G. Canadell $\oplus^{6}$, Steven J. Davis $\oplus^{7}$, Robert B. Jackson $\oplus^{8,9,10}$ and Matthew W. Jones $\oplus^{1,2}$
}

\begin{abstract}
Five years after the adoption of the Paris Climate Agreement, growth in global $\mathrm{CO}_{2}$ emissions has begun to falter. The pervasive disruptions from the COVID-19 pandemic have radically altered the trajectory of global $\mathrm{CO}_{2}$ emissions. Contradictory effects of the post-COVID-19 investments in fossil fuel-based infrastructure and the recent strengthening of climate targets must be addressed with new policy choices to sustain a decline in global emissions in the post-COVID-19 era.
\end{abstract}

Global fossil $\mathrm{CO}_{2}$ emissions have decreased by around $2.6 \mathrm{GtCO}_{2}$ in 2020 to $34 \mathrm{GtCO}_{2}$ (Fig. 1). This projected decrease, caused largely by the measures implemented to slow the spread of the COVID-19 pandemic, is about 7\% below 2019 levels, according to the analysis of the Global Carbon Project ${ }^{1}$ on the basis of multiple studies ${ }^{2-4}$ and recent monthly energy data. A $2.6 \mathrm{GtCO}_{2}$ decrease in global annual emissions has never been observed before. Yet cuts of $1-2 \mathrm{GtCO}_{2}$ per year are needed throughout the 2020s and beyond to avoid exceeding warming levels in the range $1.5^{\circ} \mathrm{C}$ to well below $2{ }^{\circ} \mathrm{C}$, the ambition of the Paris Agreement ${ }^{5}$. The drop in $\mathrm{CO}_{2}$ emissions from responses to COVID-19 highlights the scale of actions and international adherence needed to tackle climate change.

The 2020 decrease in emissions masks complex dynamics and differences in countries' responses to the COVID-19 pandemic over time. In most countries, emissions decreased at the peak of the country's confinement, by on average $27 \%$ on the basis of an updated analysis of indirect data ${ }^{3}$ (Methods). Widespread disruptions in the transport sector had the largest impact on emissions. By the end of 2020, COVID-19-related confinement measures were still acting to decrease daily emissions by around 7\% below 2019 levels (Fig. 1b), with the largest share of the decrease also due to transport emissions. Here, we put the change in 2020 emissions in the context of the recent changes in fossil $\mathrm{CO}_{2}$ emissions in the $5 \mathrm{yr}$ since the Paris Climate Agreement was adopted in 2015 and discuss the implications of COVID-19 for the evolution of global $\mathrm{CO}_{2}$ emissions. We focus on fossil $\mathrm{CO}_{2}$ emission which is the largest contributor to the rise in anthropogenic GHG.

The Paris Agreement builds on the Kyoto Protocol which was adopted in 1997, with commitments for emissions reductions for 36 mostly high-income economies (Methods). This so-called 'Annex B' country group accounted for $35 \%$ of global emissions in $2019\left(12.5 \mathrm{GtCO}_{2} \mathrm{yr}^{-1}\right)$. During the $5 \mathrm{yr}$ since the Paris Agreement was adopted, emissions in the Annex B country group decreased by $0.10 \mathrm{GtCO}_{2} \mathrm{yr}^{-1}(-0.8 \%)$ on average each year (mean of 2016-2019 compared to 2011-2015), with a further decrease of about $1.2 \mathrm{GtCO}_{2}(-9 \%)$ in 2020 alone due to the COVID-19 restrictions (Figs. 1 and 2).
Decreases in emissions were firmly set in motion by around 2005 among most (25) Annex B countries, whether accounting for emissions that occurred in a given country (territorial emissions) or around 5 years later based on all goods and services consumed in a given country even when produced elsewhere ${ }^{6}$ (consumption emissions; Extended Data Fig. 1). In the countries where emissions significantly decreased over more than a decade, previous analysis $^{7}$ highlighted that the displacement of fossil energy by renewable energy and a decreasing use of energy were the common contributing factors, accounting for $47 \%$ and $36 \%$ of the decrease in emissions (median across countries), respectively. The size of the decrease in emissions across countries was correlated to the number of climate and energy policies in place ${ }^{7}$, with a separate study corroborating that indeed the policies drove the decrease in emissions ${ }^{8}$. The decreasing use of energy was also partly explained by low growth in gross domestic product (GDP) following the 2008-2009 global financial crisis.

As a group, the 99 upper-middle-income economies accounted for $51 \%$ of global emissions in 2019 ( $17.8 \mathrm{GtCO}_{2} \mathrm{yr}^{-1}$; Methods). Of the global total, $28 \%$ was from China alone. This is also the group where emissions have risen the most, with a median growth among countries of $30 \%$ between 2005 and 2019. However, the growth in emissions in this country group has slowed considerably in the past $5 \mathrm{yr}$, with mean annual growth of $0.14 \mathrm{GtCO}_{2} \mathrm{yr}^{-1}(+0.8 \%)$ on average each year (mean of 2016-2019 compared to 2011-2015), around five times less (half when excluding China) than the growth during the previous two 5-yr periods (in absolute value; Extended Data Fig. 1). Of the 99 countries in the group, 30 have shown decreases in emissions during 2016-2019 compared to 2011-2015 (Fig. 2), suggesting that action to reduce emissions is now in motion in many countries. The growing number of climate change laws and policies in place (over 2,000 worldwide ${ }^{9}$ ) appears to have played a key role in curbing the growth in emissions in the past $5 \mathrm{yr}$ pre-COVID-19 $\left(\right.$ ref. $\left.{ }^{8}\right)$. Emissions decreased by about $0.8 \mathrm{GtCO}_{2}(-5 \%)$ in 2020 alone due to the COVID-19 restrictions (Fig. 1).

As a group, emissions originating from the 79 lowermiddle-income and low-income economies are much lower than in the other two groups, accounting for $14 \%$ of global emissions in 2019 (4.9 $\mathrm{GtCO}_{2} \mathrm{yr}^{-1}$; Methods). Emissions in this lower-income group have grown by $0.18 \mathrm{GtCO}_{2} \mathrm{yr}^{-1}(+4.5 \%)$ on average each year (mean of 2016-2019 compared to 2011-2015) with no notable slowdown at the group level (Extended Data Fig. 1). Emissions decreased in nine countries during that same time interval, although many following geopolitical instabilities (Fig. 2). Emissions decreased by about $0.4 \mathrm{GtCO}_{2}(-9 \%)$ in 2020 alone due to the COVID-19

'School of Environmental Sciences, University of East Anglia, Norwich, UK. ${ }^{2}$ Tyndall Centre for Climate Change Research, University of East Anglia, Norwich, UK. ${ }^{3} \mathrm{CICERO}$ Center for International Climate Research, Oslo, Norway. ${ }^{4}$ College of Engineering, Mathematics and Physical Sciences, University of Exeter, Exeter, England. '5MD/IPSL, École Normale Supérieure/PSL Université, CNRS, École Polytechnique, Sorbonne Université, Paris, France. ${ }^{6}$ Global Carbon Project, CSIRO Oceans and Atmosphere, Canberra, Australian Capital Territory, Australia. ${ }^{7}$ Department of Earth System Science, University of California, Irvine, Irvine, CA, USA. ${ }^{8}$ Earth System Science Department, Stanford University, Stanford, CA, USA. ${ }^{9}$ Woods Institute for the Environment, Stanford University, Stanford, CA, USA. ${ }^{10}$ Precourt Institute for Energy, Stanford University, Stanford, CA, USA. 凶e-mail: c.lequere@uea.ac.uk 
a Annual fossil $\mathrm{CO}_{2}$ emissions $\mathrm{GtCO}_{2} \mathrm{yr}^{-1}$

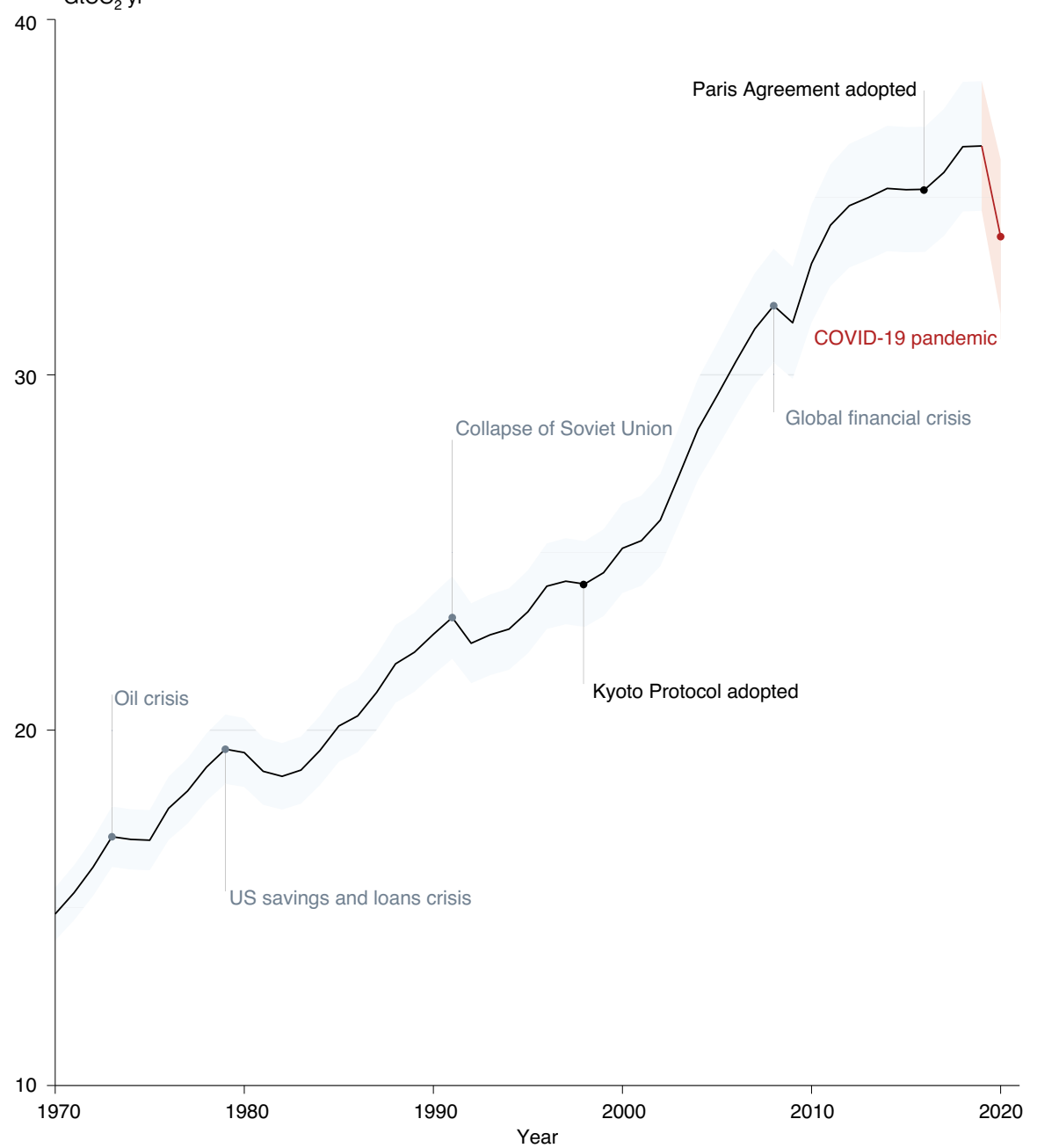

b Daily fossil $\mathrm{CO}_{2}$ emissions

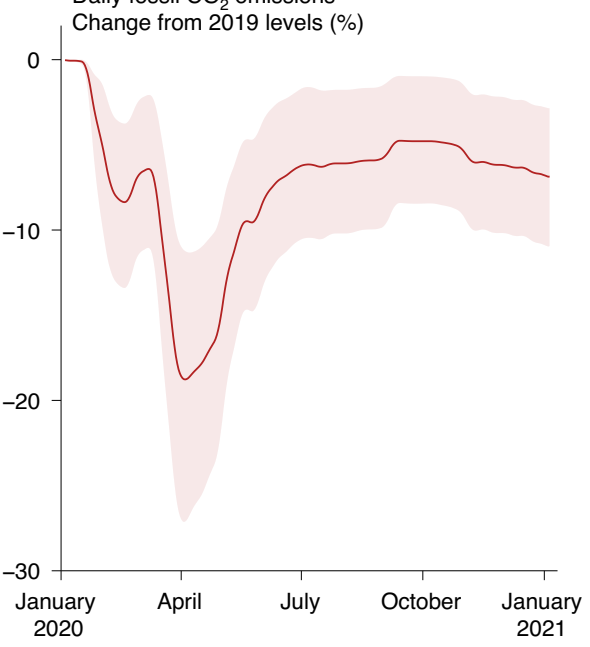

c

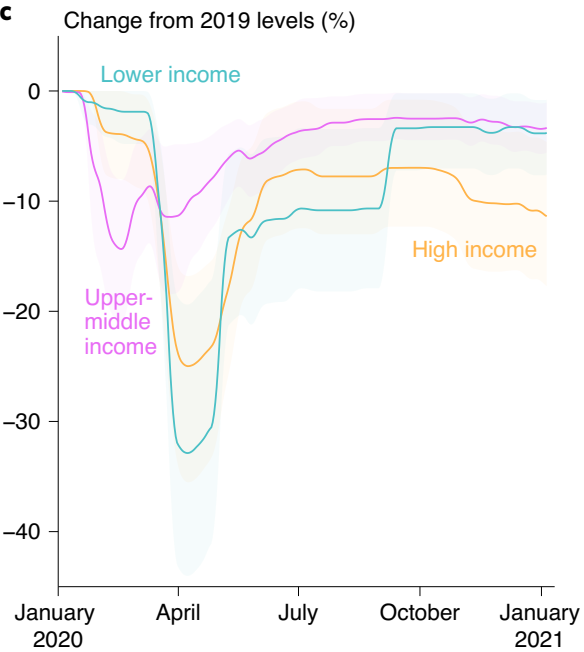

Fig. 1 | Global fossil $\mathrm{CO}_{2}$ emissions. a, Annual emissions for 1970-2019 in $\mathrm{GtCO}_{2} \mathrm{yr}^{-1}$, including a projection for 2020 (in red) on the basis of the analysis of the Global Carbon Project ${ }^{1}$ and their uncertainties (shading; Methods). b, Daily change in emissions in 2020 caused by COVID-19 restrictions, compared to a mean day in 2019, for the globe, updated from initial publication in May 2020 (ref. ${ }^{3}$ ). c, As in b but for three economic income groups: the Annex B country group of mostly high-income economies with emissions targets under the Kyoto Protocol; upper-middle-income economies (including China) as defined by the World Bank; and lower-middle-income economies and low-income economies (including India) as a single group. Global economic and energy crises are highlighted in $\mathbf{a}$, along with key international policy dates.

restrictions in that country group (Fig. 1). All countries considered, emissions decreased by $0.16 \mathrm{GtCO}_{2} \mathrm{yr}^{-1}$ on average each year among the 64 countries where emissions decreased (mean of 2016-2019 compared to 2011-2015), a tenth of what would be needed at the global level to meet the Paris climate goals, and increased 0.37 $\mathrm{GtCO}_{2} \mathrm{yr}^{-1}$ among the 150 countries where emissions increased.

Although the measures to tackle the COVID-19 pandemic will reduce emissions by about $7 \%$ in 2020 , they will not, on their own, cause lasting decreases in emissions because these temporary measures have little impact on the fossil fuel-based infrastructure that sustains the world economy ${ }^{2}$. However, economic stimuli on national levels could soon change the course of global emissions if investments towards green infrastructure are enhanced while investments encouraging the use of fossil energy are reduced ${ }^{2,10}$. Announcements as of December 2020 (ref. ${ }^{11}$ ) suggest substantial green stimulus packages with limited investments in fossil-based activities by the European Union, Denmark, France, the United Kingdom, Germany and Switzerland, but investments continue to be overwhelmingly dominated by fossil fuels in most countries, including in the United States and China. Investments in response to the global financial crisis of 2008-2009 led to an immediate rebound of emissions to their pre-crisis trajectory by 2010 (ref. ${ }^{12}$ ) (Fig. 1). Although a full rebound appears unlikely in 2021 (refs. ${ }^{13-15}$ ) given the persistence of the pandemic and the effects of pre-COVID-19 climate policy ${ }^{7,8}$, it hinges to a large extent on the alignment of economic stimulus packages and other incentives with climate objectives $^{2,16}$. Early data suggest economic drivers and other factors were driving global emissions up in December 2020, potentially offsetting the decrease caused by confinement measures ${ }^{4,17}$.

The disruption of emissions trajectories due to the COVID-19 pandemic means strategic actions now could minimize the rebound and reinforce cuts in global emissions in the long term. The nature of the disruptions in 2020 (ref. ${ }^{18}$ ), particularly affecting transportation, suggest that incentives to expedite the large-scale deployment of electric vehicles, and to encourage and make space for active transport (safe walking and cycling) in cities, are timely. Support 


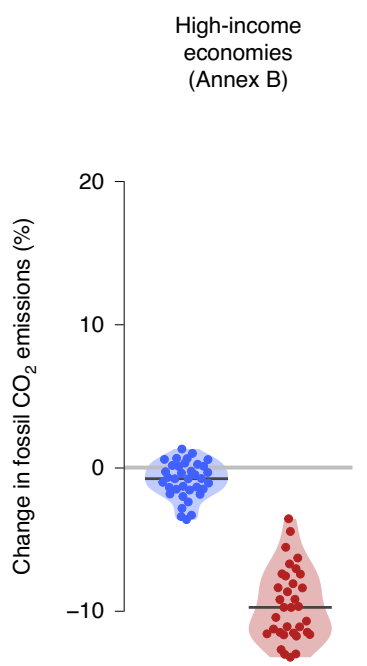

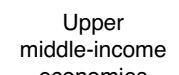

economies

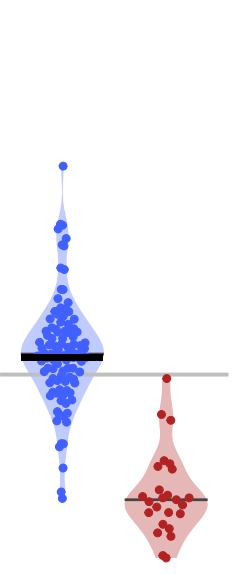

$2016-20192020^{a}$
2016-20192020

Time period
Lower-income economies

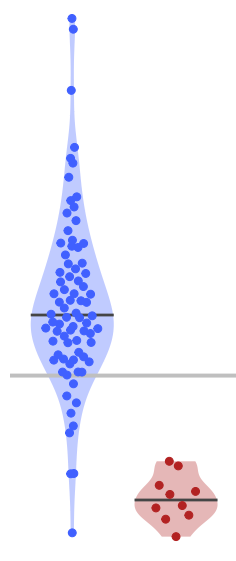

$2016-20192020^{\mathrm{a}}$
Fig. 2 | Change in fossil $\mathrm{CO}_{2}$ emissions (percent per year) in the 5 years since the adoption of the Paris Climate Agreement. Changes are shown for individual countries (dots) separated in three economic groups, as in Fig. 1. Changes are annual mean during 2016-2019 (blue) compared to the period 2011-2015, with year 2020 (red) shown separately for fewer countries. The median of the country values is shown for each country group, with the plotted violins showing the distribution of the data using a kernel density estimation. The estimated decrease in 2020 emissions is updated from a previous study and includes the effect of the COVID-19 restrictions alone ${ }^{3}$. aProjected using activity data by sector ${ }^{3}$.

to improve and promote remote communications for businesses and organizations and regional tourism, in addition to encouraging a return to public transportation as soon as it is safe to do so, could reduce total transportation needs. The resilience of renewable energy production throughout the crisis ${ }^{13,19}$, falling costs and air quality benefits, are additional incentives to support large-scale deployment of renewable energy as a post-crisis measure, which is needed to provide low-carbon electricity. These measures could curb emissions immediately, minimizing the rebound and building momentum for a change in emissions trajectory in the long term. To be at the scale necessary to meet climate objectives, such post-COVID-19 actions need to deliver a tenfold increase in emissions cuts compared to those observed during 2016-2019 among decarbonizing countries, and be accompanied by a profound disinvestment in fossil fuel-based infrastructure worldwide.

Experience from several previous crises show that the underlying drivers of emissions reappear, if not immediately, then within a few years (Fig. 1). Therefore to change the trajectory in global $\mathrm{CO}_{2}$ emissions in the long term, the underlying drivers also need to change. The growing commitments by countries to reduce their emissions to net zero within decades provides a substantial strengthening of climate ambition. This is now backed by the three biggest emitters: China (by 2060 but with few details on scope), the United States (by 2050 as detailed in President Joe Biden's electoral climate plan $)^{20}$ and the European Commission (by 2050 with strengthened ambition of at least $55 \%$ reduction by 2030 ). The effective implementation of these ambitions, both within and beyond COVID-19 recovery plans, will be essential to change global emissions trajectory. Most current COVID-19 recovery plans are in direct contradiction with countries' climate commitments ${ }^{11}$.
Year 2021 could mark the beginning of a new phase in tackling climate change. The science is established and international agreements are in place, with some evidence that growth in global $\mathrm{CO}_{2}$ emissions was already faltering before the COVID-19 pandemic. The task of sustaining decreases in global emissions of the order of billion tonnes of $\mathrm{CO}_{2}$ per year ${ }^{21}$, while supporting economic recovery and human development, and improved health, equity and well-being, lies in current and future actions. The pressing timeline is constantly underscored by the rapid unfolding of extreme climate impacts ${ }^{22}$.

\section{Online content}

Any methods, additional references, Nature Research reporting summaries, source data, extended data, supplementary information, acknowledgements, peer review information; details of author contributions and competing interests; and statements of data and code availability are available at https://doi.org/10.1038/ s41558-021-01001-0.

Received: 26 October 2020; Accepted: 2 February 2021; Published online: 3 March 2021

\section{References}

1. Friedlingstein, P. et al. Global carbon budget 2020. Earth Syst. Sci. Data 12, 3269-3340 (2020).

2. Forster, P. M. et al. Current and future global climate impacts resulting from COVID-19. Nat. Clim. Change 10, 913-919 (2020).

3. Le Quéré, C. et al. Temporary reduction in daily global $\mathrm{CO}_{2}$ emissions during the COVID-19 forced confinement. Nat. Clim. Change 10, 647-653 (2020).

4. Liu, Z. et al. Near-real-time monitoring of global $\mathrm{CO}_{2}$ emissions reveals the effects of the COVID-19 pandemic. Nat. Commun. 11, 5172 (2020).

5. Emissions Gap Report 2019: Executive Summary (UNEP, 2019).

6. Peters, G. P. et al. Growth in emission transfers via international trade from 1990 to 2008. Proc. Natl Acad. Sci. USA 108, 8903-8908 (2011).

7. Le Quéré, C. et al. Drivers of declining $\mathrm{CO}_{2}$ emissions in 18 developed economies. Nat. Clim. Change 9, 213-217 (2019).

8. Eskander, S. M. S. U. \& Fankhauser, S. Reduction in greenhouse gas emissions from national climate legislation. Nat. Clim. Change 10, 750-756 (2020).

9. Climate Change Laws of the World (Grantham Research Institute, accessed 28 January 2021); https://climate-laws.org/

10. Andrijevic, M. et al. COVID-19 recovery funds dwarf clean energy investment needs. Science 370, 298-300 (2020).

11. Greenness of Stimulus Index (Vivid Economics, accessed 14 February 2021); https://www.vivideconomics.com/casestudy/greenness-for-stimulus-index/

12. Peters, G. P. et al. Rapid growth in $\mathrm{CO}_{2}$ emissions after the 2008-2009 global financial crisis. Nat. Clim. Change 2, 2-4 (2012).

13. World Energy Outlook 2020 (IEA, 2020); https://www.iea.org/reports/ world-energy-outlook-2020

14. World Economic Outlook (IMF, 2020); http://www.imf.org

15. New Energy Outlook (Bloomberg NEF, 2020); https://about.bnef.com/ new-energy-outlook/

16. Hepburn, C. et al. Will COVID-19 fiscal recovery packages accelerate or retard progress on climate change? Oxford Rev. Eco. Policy 36, S359-S381 (2020).

17. Carbon Monitor (Carbon Monitor, accessed 29 January 2021); https://carbonmonitor.org/

18. Markard, J. \& Rosenbloom, D. A tale of two crises: COVID-19 and climate. Sust. Sci. Practice Policy 16, 53-60 (2020).

19. Bertram, C. et al. COVID-19-induced low power demand and market forces starkly reduce $\mathrm{CO}_{2}$ emissions. Nat. Clim. Change https://doi.org/10.1038/ s41558-021-00987-x (2021).

20. The Biden Plan for a Clean Energy Revolution and Environmental Justice (accessed 27 November 2020); https://joebiden.com/climate-plan/

21. Riahi, K. et al. The shared socioeconomic pathways and their energy, land use, and greenhouse gas emissions implications: an overview. Global Env. Change 42, 153-168 (2017).

22. Jones, M. W. et al. Climate Change Increases the Risk of Wildfires (ScienceBrief Review, 2020); https://sciencebrief.org/uploads/reviews/ScienceBrief_Review_ WILDFIRES_Jan2020.pdf

Publisher's note Springer Nature remains neutral with regard to jurisdictional claims in published maps and institutional affiliations.

(C) The Author(s), under exclusive licence to Springer Nature Limited 2021 


\section{Methods}

Emissions for 1990-2019. This analysis is based solely on fossil $\mathrm{CO}_{2}$ emissions, which includes the combustion of fossil fuels, the production of cement and other process emissions, as fully described elsewhere ${ }^{1}$. For territorial emissions of the 41 countries that report their emissions to the United Framework Convention on Climate Change (UNFCCC) for 1990-2018, these reports are used directly. For territorial emissions of other countries, emissions estimates are from the Carbon Dioxide Information Analysis Center (CDIAC) for the period 1990-2018 derived primarily from energy statistics published by the United Nations ${ }^{1,23}$. Territorial emissions are extended to 2019 using the growth rate in energy published by BP and converted to emissions using fuel-specific conversions ${ }^{1}$. The uncertainty is set to $\pm 5 \%$ and represents \pm 1 s.d. Consumption emissions for 1990-2018 are estimated on the basis of trade data using established methods and are taken here directly from the Global Carbon Budget 2020 update $^{1}$

Emissions for 2020. The national changes in fossil $\mathrm{CO}_{2}$ emissions during 2020 are updates from a previous study published in May 2020 (ref. ${ }^{3}$ ), and considers only the effect of the COVID-19 restrictions. Country emissions exclude international transport (aviation and shipping) as in UNFCCC guidelines, contrary to the original study ${ }^{3}$ which allocated international transport to the country where they originate. International transport here is accounted in the global emissions only. Changes in emissions are based on changes in activity for six sectors of the economy as a function of the level of confinement and uses emissions of $\mathrm{CO}_{2}$ in each sector for 71 countries representing $97 \%$ of the emissions and the degree of confinement for each country and each day of 2020. Compared to the original published study ${ }^{3}$ and the interim update ${ }^{1}$, the parameters for activity change were updated to incorporate new information that became available at the end of 2020 and further adjusted to fit available monthly data in the United States and India (Supplementary Information). These updates in parameters did not alter the results notably. The full range of uncertainty is for a decrease in 2020 emissions in the range $3-12 \%$, from uncertainty in the activity parameters ${ }^{3}$.

Comparison of the $\mathbf{2 0 2 0}$ decrease in emissions with other estimates. Compared to the published estimate, the changes in emissions from the COVID-19 restrictions during January-April 2020 is almost unchanged, with a minor update from 1.05 to $1.08 \mathrm{GtCO}_{2}$ for the world, and with minor changes for individual countries other than the scope of excluding international transport (see above). The global change in fossil $\mathrm{CO}_{2}$ emissions in other estimates as updated in the Global Carbon Budget is for a 2020 decrease of $6 \%$ based on monthly energy data available for the United States, EU 27 and India, and GDP for the rest of the world, $7 \%$ based on the Carbon Monitor ${ }^{4}$ and $13 \%$ based on Google mobility data ${ }^{2}$, for a median value of $7 \%$ based on expert judgement ${ }^{1}$, also consistent with the assessment from the International Energy Agency of $8 \%$ (ref. ${ }^{13}$ ).

Country groups follow the Annex B of the UNFCCC (with Monaco's emissions here included in France) and the World Bank classification for lending groups in 2021 (ref. ${ }^{24}$ ). A full list is provided in the Supplementary Information.

\section{Data availability}

The Global Carbon Project $\mathrm{CO}_{2}$ emissions data are available upon publication at https://www.icos-cp.eu/science-and-impact/global-carbon-budget/2020 with the daily emissions for year 2020 at https://www.icos-cp.eu/gcp-covid19. Territorial emissions to 2019 can also be accessed from globalcarbonatlas.org. Source data are provided with this paper.

\section{Code availability}

A template for estimating changes in national emissions on the basis of the confinement index during the COVID-19 pandemic will be made available here: https://www.icos-cp.eu/gcp-covid19.

\section{References}

23. Gilfillan, D. et al. Global, Regional, and National Fossil-Fuel $\mathrm{CO}_{2}$ Emissions (CDIAC, 2020); https://data.ess-dive.lbl.gov/view/ doi:10.15485/1712447

24. World Bank Country and Lending Groups (World Bank, 2020); https:// datahelpdesk.worldbank.org/knowledgebase/articles/906519-world-bank-co untry-and-lending-groups

\section{Acknowledgements}

We thank A. J. De-Gol for designing and providing Fig. 2 and Extended Data Fig. 1. We thank A. J. P. Smith for updating the confinement index used in this analysis and D. R. Willis for assistance with the data availability. C.L.Q. was funded by the Royal Society (project no. RP $\backslash R 1 \backslash 191063$ ). P.F. and G.P.P. were funded by the European Commission Horizon 2020 (H2020) 4C project (821003), R.M.A. and C.L.Q. by the H2020 VERIFY project (776810), M.W.J. by the H2020 CHE project (776186), G.P.P. by the H2020 Paris Reinforce project (820846) and J.G.C. by the Australian National Environmental Science Programme-Earth Systems and Climate Change Hub.

\section{Author contributions}

C.L.Q., G.P.P., P.F., J.G.C. and R.B.J. conceived and designed the project. R.M.A. provided emissions data. C.L.Q. and M.W.J. produced the analysis. All the authors contributed to the interpretation of the results and wrote the paper.

\section{Competing interests}

The authors declare no competing interests.

\section{Additional information}

Extended data is available for this paper at https://doi.org/10.1038/s41558-021-01001-0.

Supplementary information The online version contains supplementary material available at https://doi.org/10.1038/s41558-021-01001-0.

Correspondence and requests for materials should be addressed to C.L.Q.

Peer review information Nature Climate Change thanks Sam Fankhauser, H. Damon Matthews, Hannah Ritchie and the other, anonymous, reviewer(s) for their contribution to the peer review of this work.

Reprints and permissions information is available at www.nature.com/reprints. 
High-income economies (Annex B)
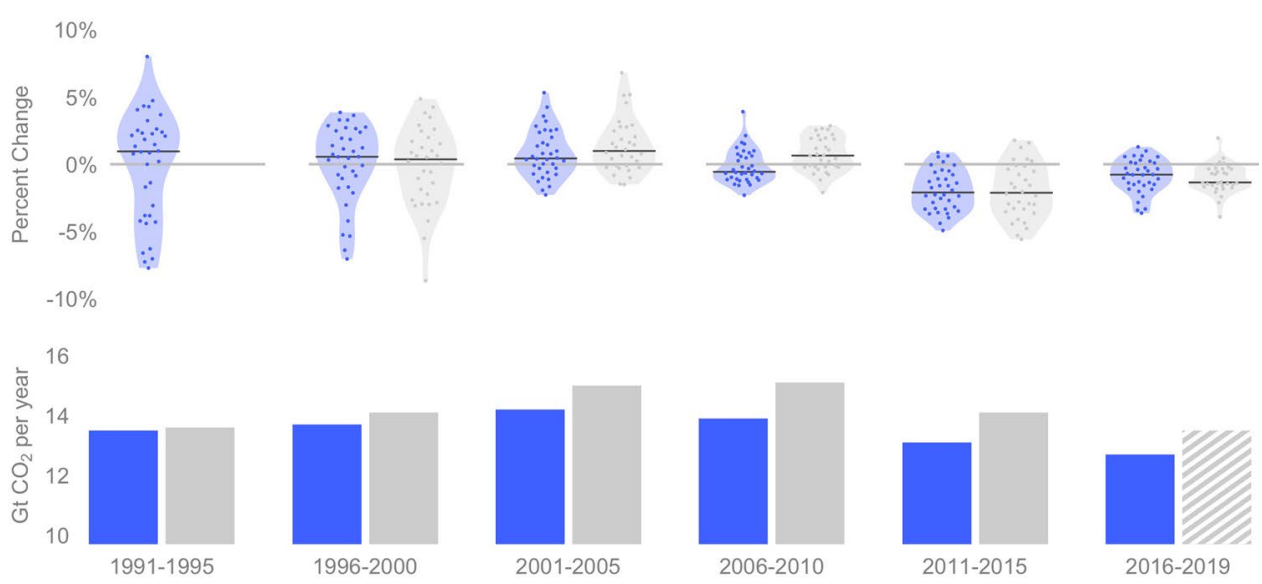

2011-2015

2016-2019

\section{Upper middle-income economies}
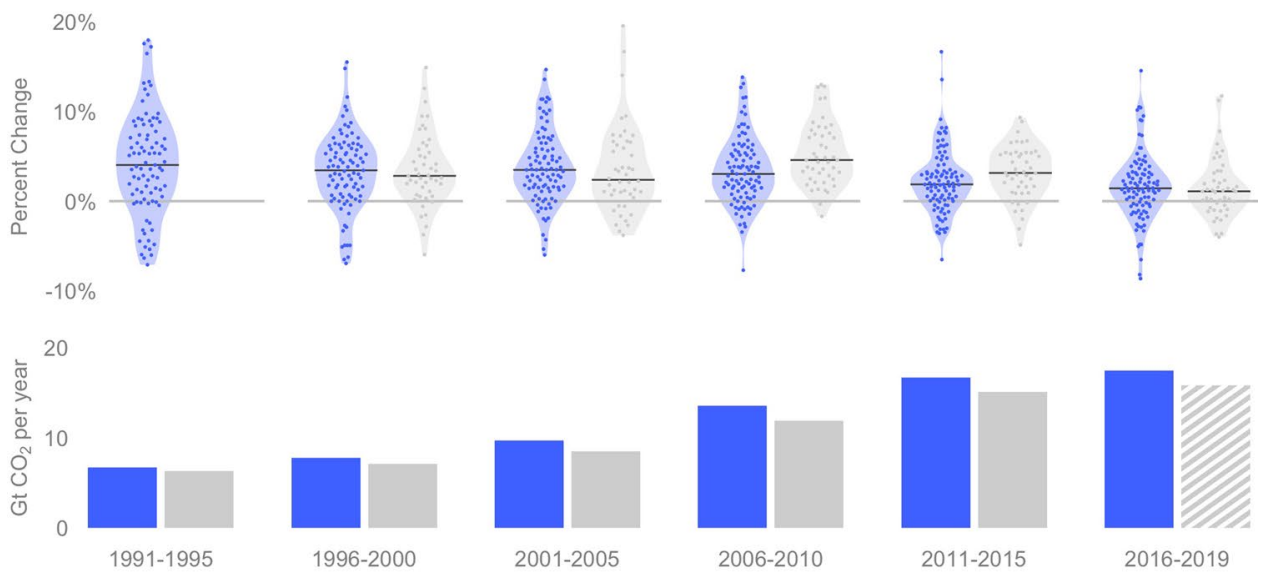

2006-2010

2011-2015

2016-2019

Lower-income economies
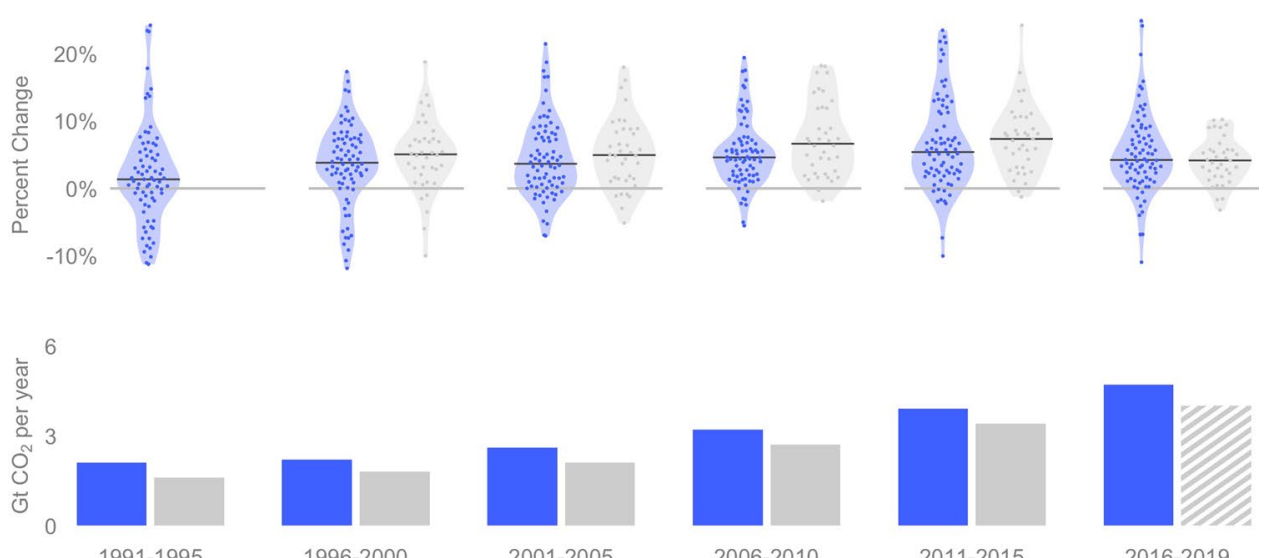

2006-2010
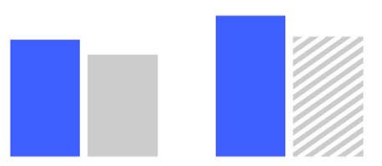

2011-2015 
Extended Data Fig. 1 | Evolution of fossil $\mathrm{CO}_{2}$ emissions in 5-year periods since 1991 (as in Fig. 2). Mean annual changes are shown for individual countries (dots, in per cent) separated in three economic groups as in Fig. 2, with the median for each country group and the distribution of the data shown using a kernel density estimation. The mean emissions for each group and each period are shown at the bottom, based on territorial emissions following UNFCCC accounting, and based on consumption emissions (note variable y-axis; $\mathrm{GtCO}_{2} \mathrm{yr}^{-1}$ ). 